\title{
Differences in postprandial responses to fat and carbohydrate loads in habitual high and low fat consumers (phenotypes)
}

\author{
J. E. Blundell*, J. Cooling and N. A. King \\ BioPsychology Group, School of Psychology, University of Leeds, Leeds LS2 9JT, UK
}

(Received 30 August 2001 - Revised 21 February 2002 - Accepted 23 March 2002)

\begin{abstract}
The present study investigated metabolic responses to fat and carbohydrate ingestion in lean male individuals consuming an habitual diet high or low in fat. Twelve high-fat phenotypes (HF) and twelve low-fat phenotypes (LF) participated in the study. Energy intake and macronutrient intake variables were assessed using a food frequency questionnaire. Resting (RMR) and postprandial metabolic rate and substrate oxidation (respiratory quotient; RQ) were measured by indirect calorimetry. HF had a significantly higher RMR and higher resting heart rate than LF. These variables remained higher in HF following the macronutrient challenge. In all subjects the carbohydrate load increased metabolic rate and heart rate significantly more than the fat load. Fat oxidation (indicated by a low RQ) was significantly higher in HF than in LF following the fat load; the ability to oxidise a high carbohydrate load did not differ between the groups. Lean male subjects consuming a diet high in fat were associated with increased energy expenditure at rest and a relatively higher fat oxidation in response to a high fat load; these observations may be partly responsible for maintaining energy balance on a high-fat (high-energy) diet. In contrast, a low consumer of fat is associated with relatively lower energy expenditure at rest and lower fat oxidation, which has implications for weight gain if high-fat foods or meals are periodically introduced to the diet.
\end{abstract}

Fat intake: Energy expenditure: Energy balance: Respiratory quotient: Dietary induced thermogenesis

Stability of body weight and body composition requires that, over a substantial time period, energy intake equals energy expenditure and that intakes of protein, carbohydrate and fat must equal the oxidation of each nutrient (energy balance). Another way of stating this is that the respiratory quotient (RQ), which is the ratio of $\mathrm{CO}_{2}$ produced to $\mathrm{O}_{2}$ consumed, must equal the food quotient, which is the ratio of $\mathrm{CO}_{2}$ produced to $\mathrm{O}_{2}$ consumed if the food were oxidised. If these conditions are not met changes in body stores of protein, carbohydrate and fat will occur, which will affect overall body weight.

Of all the possible causes of a positive energy balance leading to weight gain, the excessive intake of fat has been investigated extensively and has been repeatedly implicated as a major risk factor for obesity. This is because fat has been found to be the least satiating of all nutrients, yet it has the greatest energy density, is oxidised least preferentially and has an unlimited storage capacity. A number of authors have recently reviewed the issue (Westerterp, 1993; Blundell \& Macdiarmid, 1997; Golay
\& Bobbioni, 1997). However, the existence of many low to normal weight individuals (allowing for age-related changes in BMI) among those eating a high-fat diet (Macdiarmid et al. 1996) suggests the possibility that some high fat consumers may be protected from the weight-inducing properties of a high-fat diet. This protection could be physiological (altered metabolic rate or fat oxidation) or behavioural (physical activity). Our laboratory has undertaken a programme of research to investigate lean high fat consumers by comparing them with individuals consuming a diet low in fat; these studies have revealed differences in appetite control (Cooling \& Blundell, 1998a), basal metabolism (Cooling \& Blundell, 1998b), physical activity patterns (Cooling \& Blundell, 2000), and circulating levels of leptin and triacylglycerols (Cooling et al. 1998).

The present study measures fat oxidation (via RQ) and energy expenditure in two components of total energy expenditure: resting metabolic rate (RMR) and dietary induced thermogenesis (DIT). DIT was measured in

Abbreviations: DIT, dietary induced thermogenesis; FFQ, food frequency questionnaire; MAC, macronutrient; RMR, resting metabolic rate; RQ, repiratory quotient.

* Corresponding author: John Blundell, fax +44 1133436674 email Johneb@psychology.leeds.ac.uk 
response to both a high-fat and high-carbohydrate equienergetic nutrient load in order to investigate differences between high and low fat consumers in the ability to deal with the nutrient challenge. Any differences arising could of course be due to pre-existing biological dispositions or to an adaptation resulting from long-term exposure of the body to large quantities of consumed fat. Whatever the mechanism, such differences should be expected since a study in human subjects designed to determine the contribution of various determinants of basal lipolysis found that percentage fat intake was the variable with the highest correlation with basal lipolysis, which alone explained $32 \%$ of variation (Calles-Escandon \& Driscoll, 1995); additionally, animal studies have indicated distinct changes in oxidative metabolism (Mayes \& Felts, 1967) and specific metabolism of fat (Reed et al. 1991) in rats fed high-fat diets. An aspect that must be considered in the processes leading to obesity is a metabolic difference between subjects in the handling of fat. A large volume of evidence has been presented to show that high-fat diets promote obesity. However, in studies on rats given ad libitum access to a high-fat diet, although most rats readily become obese some avoid obesity; the rats remaining lean were found to have a lower daily RQ than obese rats suggesting that the obesity-resistant rats increased fat oxidation in response to increased fat intake more than the obese rats (Chang et al. 1990). It can be proposed that there are individual differences in the extent to which a high intake of fat results in increased fat oxidation and body-fat gain, and thus there are differences in the susceptibility of individuals to the effects of fat in the development of obesity. In a study by Thomas et al. (1992) both lean and obese subjects were able to match carbohydrate oxidation to carbohydrate intake following a 7-d high-carbohydrate diet but lean individuals were found to be more efficient than obese in matching fat oxidation to fat intake following a high-fat diet (although both groups were in a positive fat balance). Restrained eating subjects have similarly shown a decreased fat oxidation compared with unrestrained eaters in response to a high-fat diet, resulting in a positive fat balance for restrained-eating subjects, possibly explaining their higher susceptibility to becoming obese (Verboeketvan de Venne et al. 1994).

DIT can account for about $10 \%$ of total energy expenditure, and an impaired dietary thermogenic response is implicated in the pathogenesis of obesity (Saris, 1996). The impact of DIT on energy balance and obesity in man is still controversial, however. Studies of DIT show wide variations in methodology in terms of the meal preload (differences in DIT have been observed depending on the energy, volume and macronutrient (MAC) content, and between solid or liquid food (Young, 1995)), the duration of DIT measurement (usually ranging from 60-360 min), the types of subjects used (differences are observed between males and females and between young and old subjects, even when controlling for body composition (Visser et al. 1995)), and, because of the time-consuming nature of the experiments, subject numbers are often low, and so the high variations in DIT measurement lead to low statistical power in studies with a sample size $<10$. It is not surprising, therefore, that conflicting data exist; in a review by D'Alessio et al. (1988) fifteen papers are cited reporting a reduced DIT in obese subjects compared with lean subjects and twelve papers reporting no differences between the groups.

The present study has measured RQ in the fasted state and DIT in individuals habitually consuming different diets. The study was designed to disclose whether the metabolic responses to fat and carbohydrate differ and whether habitual high and low fat consumers (phenotypes) have distinct responses to each nutrient.

\section{Methods \\ Experimental design}

The purpose of the present study was to assess resting metabolic rate via indirect calorimetry and heart rate in high and low fat consumers, and to monitor postprandial thermogenesis and fuel oxidation in response to a highfat or high-carbohydrate challenge.

The present study was a repeated measures $2 \times 2$ design; both high and low fat consumers participated in two experimental conditions. The challenge took the form of a milkshake drink: condition A (high-fat challenge); condition B (high-carbohydrate challenge).

\section{Subjects}

Twenty-four healthy, non-obese males were recruited from the student and staff population of Leeds University. All volunteers who responded to advertisements were asked to complete a food frequency questionnaire (FFQ) (Margetts et al. 1989). Analysis of the FFQ was used to determine the habitual diets of each volunteer. High fat consumers were defined as eating $>43 \%$ energy from fat, and low fat consumers $<33 \%$; additionally, any high fat consumer with a particularly low absolute (i.e. g/d) intake of fat or low fat consumer with a high absolute intake was excluded such that there was no overlap in absolute fat intake between the groups.

All subjects were non-smokers, in the age range 19-25 years and had a BMI $<26 \mathrm{~kg} / \mathrm{m}^{2}$.

\section{Indirect calorimetry}

Subjects arrived at the Human Appetite Research Unit, University of Leeds, at approximately 09.00 hours having fasted for $12 \mathrm{~h}$. The height of subjects was measured using a stadiometer, and weight was measured, following voiding, on a digital balance (Salter West Bromwich, UK). Body fat was measured by the impedance procedure (Spacelabs BC-300). After these measurements the subjects lay supine on a bed in a thermoneutral environment and remained at bed rest throughout the study period. Heart rate was recorded every $15 \mathrm{~s}$ throughout the procedure (Polar sports tester PE4000, Kompele, Finland). Resting $\mathrm{O}_{2}$ consumption and $\mathrm{CO}_{2}$ production were measured by using a ventilated-hood indirect calorimetry system (GEM; Nutren, Manchester, UK); the principle of the ventilated hood system has been described previously (Weststrate, 1993). After $30 \mathrm{~min}$ of steady baseline 
Table 1. Characteristics of the macronutrient challenge

\begin{tabular}{lccrcc}
\hline & \multicolumn{2}{c}{ Condition $A^{*}$} & & \multicolumn{2}{c}{ Condition B十 } \\
\cline { 2 - 3 } \cline { 5 - 6 } & $\mathrm{g}$ & \% energy & & $\mathrm{g}$ & \% energy \\
\hline Energy (kJ) & & 2092 & & 2092 \\
Volume (ml) & 500 & & 500 \\
Fat content & 43.8 & 78.8 & & 0.7 & 1.3 \\
Carbohydrate content & 26.6 & 19.9 & & 120.5 & 90.4 \\
Protein content & 1.6 & 1.3 & & 10.4 & 8.3 \\
\hline
\end{tabular}

*High-fat milkshake containing $92 \mathrm{~g}$ double cream (Safeway, Leeds, UK), $25 \mathrm{~g}$ milk-shake powder (Nesquik, York, UK), made up to $500 \mathrm{ml}$ with water.

† High-carbohydrate milkshake containing $305.3 \mathrm{ml}$ skimmed milk (Safeway), $80.6 \mathrm{~g}$ (*Pur01921 glucose polymer (Cerestar, Manchester)), $25 \mathrm{~g}$ milkshake powder (Nesquik), made up to $500 \mathrm{ml}$ with water.

measurements the ventilated hood was removed and one of the two milkshake drinks was given (the drinks were presented in a counterbalanced order); the drink was consumed through a drinking straw and the subject was asked to drink all of the milkshake within $5 \mathrm{~min}$, after which the subject was allowed to void if necessary. The subject was then returned to the hood and indirect calorimetry was continued for a further $180 \mathrm{~min}$. Subjects were instructed to remain awake but motionless throughout the procedure; they were allowed to watch television.

RMR (calculated from the Weir (1949) equation) and heart rate were taken as the average value of $30 \mathrm{~min}$ of steady baseline measures; this was typically after 10$15 \mathrm{~min}$ of the subject lying under the ventilated hood. Thereafter (after the milkshake drink), results were averaged over 20 min periods.

\section{Macronutrient challenge}

The high-fat or high-carbohydrate challenge comprised milkshake drinks that were of equal volume and weight, and of fixed energy, but differed in macronutrient composition (Table 1). The flavour of the milkshake (banana or strawberry, Nesquik, York, UK) was determined by the preference of the subject.

\section{Data analysis}

Metabolic parameters and heart rate were analysed using repeated measures ANOVA using MAC and time (TIME) as within-subject factors and high or low fat status (GROUP) as a between-subjects factor. Individual differences between conditions and groups were analysed using paired and unpaired $t$ tests. Analysis was performed using SPSS software (version 9.0; USA).

\section{Results}

\section{Subject characteristics}

Details of the twenty-four recruited subjects, twelve high fat and twelve low fat consumers, can be seen in Table 2 . The macronutrient variables and energy intake were derived from analysis of the FFQ. Percentage body fat was measured by the bioimpedance procedure. Independent $t$ tests were carried out on each variable and significant differences were found between the two groups on energy intake, fat intake, percentage fat intake and percentage carbohydrate intake. The high fat and low fat consumers met the criteria for inclusion in the groups. High fat consumers consumed significantly greater absolute amounts of fat and a greater fat energy percentage but a smaller carbohydrate energy percentage than low fat consumers did. The intake of protein (percentage and absolute) did not differ between high and low fat consumers. Although the FFQ is not designed to provide a measure of daily energy intake (i.e. $\mathrm{kJ} / \mathrm{d}$ ), this can be calculated and indicates that high fat consumers have greater energy intakes than low fat consumers. This observation is consistent with findings from the analysis of the Diet and Nutrition Survey of British Adults (Macdiarmid et al. 1996) and the Leeds High Fat Study (Macdiarmid et al. 1995).

\section{Basal physiology}

RMR, resting $\mathrm{O}_{2}$ consumption and resting heart rate were significantly higher in high fat consumers than low fat consumers. The difference in RMR remained significant when expressed per kilogram of lean body mass; calculated from

Table 2. Characteristics of groups of high and low fat consumers on key variables (Mean values and standard errors)

\begin{tabular}{|c|c|c|c|c|}
\hline & \multicolumn{2}{|c|}{ High fat consumers } & \multicolumn{2}{|c|}{ Low fat consumers } \\
\hline & Mean & SE & Mean & SE \\
\hline Age (years) & $20 \cdot 7$ & 0.48 & $21 \cdot 6$ & 0.7 \\
\hline BMI $\left(\mathrm{kg} / \mathrm{m}^{2}\right)$ & $21 \cdot 2$ & 1.5 & 22.4 & 0.6 \\
\hline Body fat (\%) & $11 \cdot 1$ & 1.29 & $11 \cdot 4$ & 1.3 \\
\hline Energy intake (MJ/d) & $12 \cdot 29$ & 0.983 & $9 \cdot 47^{\star}$ & 0.485 \\
\hline Protein intake $(\mathrm{g} / \mathrm{d})$ & $109 \cdot 9$ & $9 \cdot 7$ & $87 \cdot 2$ & $6 \cdot 1$ \\
\hline Carbohydrate intake (g/d) & $327 \cdot 3$ & $22 \cdot 2$ & $321 \cdot 2$ & $16 \cdot 0$ \\
\hline Fat intake $(\mathrm{g} / \mathrm{d})$ & $145 \cdot 8$ & 13.9 & $79 \cdot 4^{\star \star}$ & $5 \cdot 1$ \\
\hline Protein intake (\% energy) & $15 \cdot 0$ & 0.4 & $15 \cdot 3$ & 0.7 \\
\hline Carbohydrate intake (\% energy) & $42 \cdot 8$ & $1 \cdot 2$ & $54 \cdot 1^{\star \star}$ & $1 \cdot 8$ \\
\hline Fat intake (\% energy) & $44 \cdot 2$ & 0.7 & $31 \cdot 4^{\star *}$ & 0.9 \\
\hline
\end{tabular}


Table 3. Resting physiological data*

(Mean values and standard errors)

\begin{tabular}{|c|c|c|c|c|}
\hline & \multicolumn{2}{|c|}{ High fat consumers } & \multicolumn{2}{|c|}{ Low fat consumers } \\
\hline & Mean & SE & Mean & SE \\
\hline $\operatorname{RMR}(\mathrm{MJ} / \mathrm{d})$ & $6 \cdot 866$ & 0.12 & $6 \cdot 230 \dagger$ & 0.20 \\
\hline BMR $(\mathrm{kJ} / \mathrm{kg}$ lean mass per $\mathrm{d})$ & 107 & 2.5 & $97.9+$ & $2 \cdot 1$ \\
\hline $\mathrm{O}_{2}$ consumption ( $\mathrm{ml} \mathrm{O}_{2} / \mathrm{kg}$ per min) & $3 \cdot 24$ & 0.09 & $2.93 \dagger$ & 0.05 \\
\hline Resting respiratory quotient & 0.839 & 0.007 & $0.877 \dagger$ & 0.013 \\
\hline Resting heart rate (beats/min) & $66 \cdot 8$ & $1 \cdot 7$ & $56 \cdot 2 \dagger$ & 1.7 \\
\hline
\end{tabular}

* For details of subjects, see Table 2 and p. 126.

Mean values were significantly different from those of the high fat consumers: $\dagger P<0.05(t=2.26)$ (independent $t$ test).

a regression equation derived from energy expenditure and lean body mass (Ravussin \& Bogardus, 1989). Resting RQ was significantly lower in high fat than low fat consumers (Table 3).

\section{Postprandial physiology}

The mean values taken across each experimental condition can be seen in Table 4. Metabolic rate at rest (RMR) remained consistently higher in high fat than in low fat consumers (Fig. 1), although this was marginally nonsignificant $(P=0 \cdot 07)$. However, a strong effect of MAC was observed ( $P=0 \cdot 008)$, with higher RMR values following the carbohydrate load than in the fat load (Fig. 2).

Mean RQ over each condition demonstrated main effects of GROUP $(P=0.0460)$ and MAC $(P<0 \cdot 000)$; high fat consumers have consistently lower RQ values than low fat consumers and RQ values are higher following the carbohydrate load than the fat load (Fig. 3). Further analysis revealed that RQ in high fat consumers following the fat challenge was significantly lower than in low fat consumers $(P=0.038)$, but following the carbohydrate challenge the effect was much weaker and not significant. Furthermore, when time is factored into the analysis it is revealed that following the MAC challenge in high fat consumers the time taken for the RQ to significantly differ between the high-fat and -carbohydrate challenge was approximately $40 \mathrm{~min}$, whereas in low fat consumers the time was $100 \mathrm{~min}$.
Mean heart rate demonstrated a strong effect of GROUP $(P=0.05)$, with heart rates among high fat consumers consistently higher than low fat consumers. However, when heart rate is expressed from baseline values a strong effect of MAC is seen $(P=0 \cdot 009)$, with heart rate higher following the carbohydrate challenge than the fat challenge; the pattern of heart rate effects are consistent with the pattern of metabolic rate shown in Figs. 1 and 2.

\section{Discussion}

The present study has revealed distinct physiological responses to fat and carbohydrate loads in habitual high and low fat consumers. Previous studies in high and low fat consumers have reported differences in basal physiology (Cooling \& Blundell, 1998b) (replicated in the present study), along with differing patterns of hunger and appetite control (Cooling \& Blundell, 1998a), and patterns of physical activity (Cooling \& Blundell, 2000). Taken together the results suggest a possible mechanism responsible for achieving energy balance, and preventing weight gain on a high-fat diet.

The consumption of a diet high in fat will almost inevitably lead to a high energy intake and the risk of a positive energy balance. However, young adult males consuming such a diet are virtually indistinguishable from low fat consumers in terms of body weight, BMI, and body fat. Therefore it appears that energy balance is achieved, and weight

Table 4. Postprandial physiological responses following fat and carbohydrate $(\mathrm{CHO})$ challenge in high and low fat consumers ${ }^{*}$

(Mean values and standard errors)

\begin{tabular}{|c|c|c|c|c|c|c|c|c|}
\hline \multirow{3}{*}{ Challenge... } & \multicolumn{4}{|c|}{ High fat consumers } & \multicolumn{4}{|c|}{ Low fat consumers } \\
\hline & \multicolumn{2}{|c|}{ Fat } & \multicolumn{2}{|c|}{$\mathrm{CHO}$} & \multicolumn{2}{|c|}{ Fat } & \multicolumn{2}{|c|}{$\mathrm{CHO}$} \\
\hline & Mean & SE & Mean & SE & Mean & SE & Mean & SE \\
\hline $\mathrm{MR}(\mathrm{MJ} / \mathrm{d}) \dagger$ & $7 \cdot 519$ & $0 \cdot 21$ & $7 \cdot 795$ & 0.28 & 6.786 & 0.28 & $7 \cdot 138$ & 0.31 \\
\hline MR (kJ/d above baseline)† & 661 & 209 & 916 & 188 & 615 & 105 & 845 & 113 \\
\hline Respiratory quotient†‡ & 0.85 & 0.01 & 0.92 & 0.01 & 0.89 & 0.01 & 0.94 & 0.02 \\
\hline Heart rate (beats/min) $\ddagger$ & $71 \cdot 6$ & $2 \cdot 0$ & $72 \cdot 1$ & 2.9 & $59 \cdot 6$ & $2 \cdot 1$ & $61 \cdot 3$ & $2 \cdot 1$ \\
\hline Heart rate (beats/min above baseline)† & 3.5 & 0.8 & $6 \cdot 6$ & 1.0 & 2.9 & 0.9 & 5.7 & $1 \cdot 1$ \\
\hline
\end{tabular}

$\mathrm{CHO}$, carbohydrate; MR, metabolic rate.

${ }^{*}$ For details of subjects, see Table 2 and p. 126, and for details of challenges, see Table 1.

† ANOVA effect of macronutrient $(\mathrm{F}[1,22]=4.61, P<0.05)$.

$\ddagger$ ANOVA effect of group $(\mathrm{F}[1,22]=8 \cdot 26, P<0.05)$. 


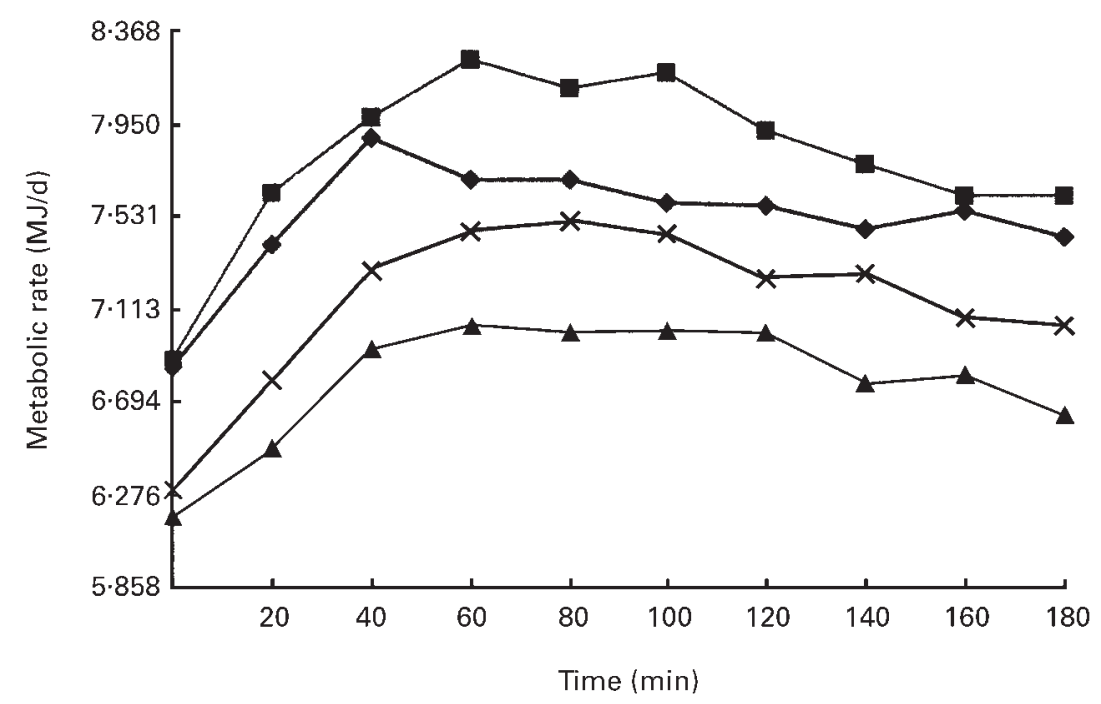

Fig. 1. Profile of metabolic rate responses to fat, $(-\downarrow,-\mathbf{-}-)$ and carbohydrate $(-\boldsymbol{\square}-,-\times-)$ challenges in high $(--,-\boldsymbol{-}-)$ and low $(-\boldsymbol{\Delta}-,-\times-)$ fat consumers.

gain prevented, by a combination of physiological and behavioural factors.

Results from the present study confirm previous findings that high fat consumers have a higher RMR than low fat consumers, with high fat consumers displaying a RMR approximately $10 \%$ (about $630 \mathrm{~kJ}(150 \mathrm{kcal}) / \mathrm{d}$ ) higher than low fat consumers. Taken at face value $630 \mathrm{~kJ} / \mathrm{d}$ is not a large amount of energy, however over time this difference is equivalent to $4400 \mathrm{~kJ}(1050 \mathrm{kcal}) /$ week or $230 \mathrm{MJ}(55000 \mathrm{kcal}) / y e a r$. The mechanism for this may involve the recently discovered human uncoupling protein-3, which has been shown in mice to increase energy expenditure and normalise body weight in high-fat hyperphagic conditions (Clapham et al. 2000). In addition, a high-fat diet has been shown to increase the expression of uncoupling protein mRNA in skeletal muscle of human subjects (Schrauwen et al. 2001). Highlighted in the present study is the finding that high fat consumers show a consistently lower RQ (in the fasted and postprandial state) than low fat consumers and therefore oxidise more fat, which helps to maintain fat balance (which approximates to energy balance). In the fasted state the RQ in high fat consumers approximated to $53 \%$ of energy expenditure derived from fat oxidation; in low fat consumers this figure was $39 \%$. Following the MAC challenge high and low fat consumers demonstrated a similar response to carbohydrate by increasing carbohydrate oxidation (increasing RQ). However, following the high-fat challenge high fat consumers showed a significantly lower RQ than low fat consumers, indicating greater fat oxidation in high fat consumers. Additionally the metabolic response to the ingestion of fat was quicker in high fat consumers: following fat intake

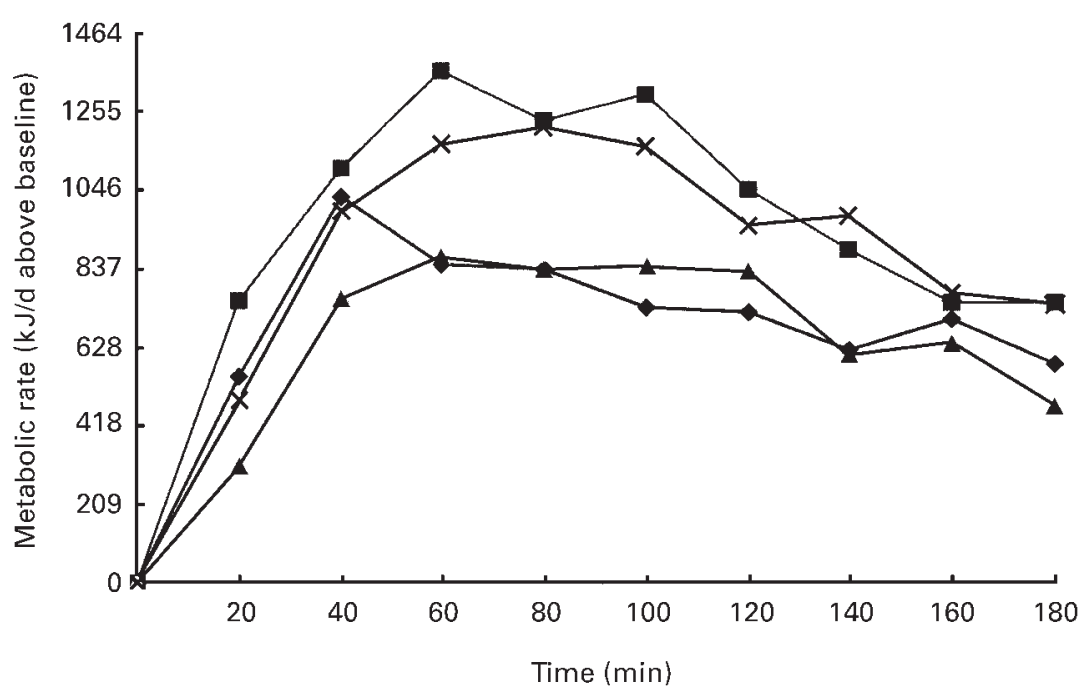

Fig. 2. Profile of metabolic rate responses to fat $(--,-\mathbf{-}-)$ and carbohydrate $(-\square,-\times-)$ challenges in high $(--,-\mathbf{-}-)$ and low $(-\mathbf{-}-,-\times-)$ fat consumers expressed relative to baseline values. 


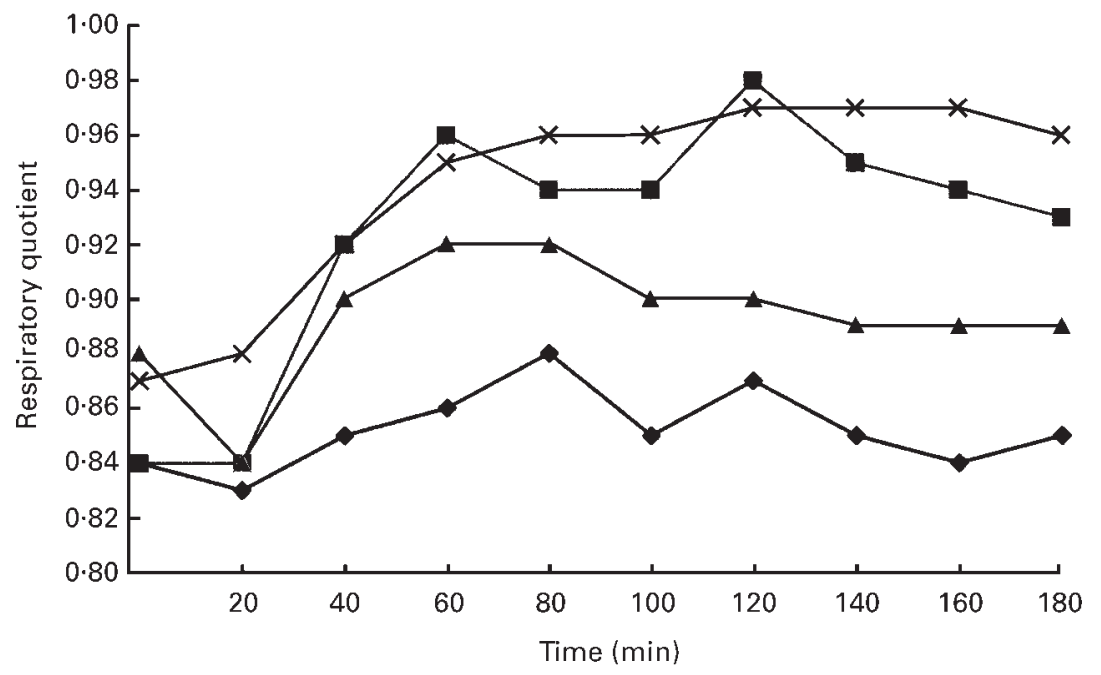

Fig. 3. Profile of respiratory quotient responses to fat $(--,-\mathbf{-}-)$ and carbohydrate $(-\boldsymbol{-}-,-\times-)$ challenges in high $(--,-\boldsymbol{-}-)$ and low $(-\mathbf{-}-,-\times-)$ fat consumers.

RQ in high fat consumers was significantly lower than values following carbohydrate ingestion within $40 \mathrm{~min}$; in low fat consumers the time for this response was, on average, within $100 \mathrm{~min}$. In summary, following a high fat load high fat consumers oxidise more fat than low fat consumers and commence this oxidation $60 \mathrm{~min}$ before low fat consumers.

It would appear that the high fat consumers seen in the present research were not genetically predisposed to obesity, at least at this particular age: the ability to match fat oxidation to fat intake, as seen in the cohorts of high fat consumers used here, is absent in individuals genetically predisposed to obesity and in post-obese subjects (Astrup et al. 1996). This, along with other adaptive or naturally occurring mechanisms to maintain energy balance, suggests that the cohorts of high fat consumers used in these studies are protected, to some degree, from weight gain, at least at their present age. This does not mean, however, that high fat consumers are immune to weight gain and obesity. The large increase in obesity over the last 50 years or so has occurred over a period of time that is too short to be caused by changes in the frequency of obesity genes or susceptible alleles (Bouchard, 1996); this increase can only be due to a large number of individuals in chronic positive energy balance. Although apparent protective mechanisms have been observed among high fat consumers in studies of high and low fat consumers there has been no prospective study to monitor the body weight of high and low fat consumers over a long period of time. It has been hypothesised that the high fat consumers (phenotypes) are slowly gaining weight despite protective mechanisms (without which they may already have become obese) (Blundell \& Cooling, 2000). It should be stressed here that a high-fat diet is not the only risk factor for the development of obesity; previous studies have shown that a high BMI is more associated with being older, or being female, than with the consumption of a diet high in fat (Macdiarmid et al. 1997). All the subjects used in the present study were not representative of the whole population, being male in the age range 18-30 years. Therefore the conclusions made from this thesis cannot be generalised to the entire population. We have predicted that the ability (or partial ability) of high fat consumers to maintain energy balance may decline as they advance into middle age. Such a theory is supported by evidence: relative to younger women, older women have a reduced ability to oxidise dietary fat when they consume large high-fat meals, resulting in greater fat deposition (Melanson et al. 1997). The leptin system may also be involved: the high levels of leptin among obese human subjects suggests that obesity is not caused by an absolute leptin deficiency per se, but by leptin resistance (Auwerx \& Staels, 1998); the long-term exposure to high leptin levels as in habitual high fat consumers (Cooling et al. 1998) may result in an eventual leptin resistance and its ability to help maintain fat balance will be lost. Important here is the distinction between the leptin levels in response to a habitual high-fat diet and the response to an acutely imposed high fat load. Additionally, the persistence of a high-fat diet into middle and older age would probably interact with decreasing levels of physical activity and a lowering of RMR.

These findings indicate the possible existence of a dilemma: habitual low fat consumers may be prone to weight gain if high-fat foods are periodically introduced to the diet. Due to the relatively low storage capability but yet high oxidative hierarchy of carbohydrate the balance of carbohydrate within the body is excellent, therefore the consumption of a diet high in carbohydrates will more likely lead to a preservation of energy balance and a stable body weight. However, in other studies using low fat consumers it has been shown that they are susceptible to occasional periods of very high fat intakes, over an entire day or within one meal (Macdiarmid et al. 1997). Although the effect is much more pronounced in high fat consumers, low fat consumers are also susceptible to passive overconsumption of fat, especially when hungry (Cooling \& Blundell, 1998a). It is well accepted that, 
unlike carbohydrate and protein, fat is only weakly coupled with fat oxidation and the consumption of a high-fat diet is required for several consecutive days in order to balance fat oxidation with fat intake (Ravussin \& Tataranni, 1997; Schrauwen et al. 1997; Smith et al. 2000). A high intake of fat in low fat consumers could therefore create a positive fat balance; if this was not compensated for, either metabolically (oxidation) or behaviourally (increased activity, decreased intake) it could result in weight gain. Such a high fat load consumed by high fat consumers would not cause such a positive fat balance as they are habituated to a high fat intake and to the consequent higher level of fat oxidation. Such a situation was recreated in the present study. The consumption of a high-carbohydrate milkshake resulted in an increase in RQ (increases in carbohydrate oxidation) among previously fasted high and low fat consumers. This was expected as carbohydrate (in the absence of alcohol) is at the top of the oxidative hierarchy; the RQ response to the carbohydrate load was not significantly different between the groups. In contrast following the consumption of a high-fat milkshake the inability of low fat consumers to oxidise fat was reflected in the lowering of RQ among high fat consumers (indicating more fat oxidation), while the RQ in low fat consumers was higher than that of high fat consumers, indicating that they were mainly oxidising the carbohydrate component of the high-fat milkshake. Although not measured it can be assumed that a degree of fat deposition took place. It is possible that those individuals who seem to be able to eat a high-fat diet and avoid weight gain may not be better off with a lowering of fat intake (at least for body-weight control).

The higher RQ and lower RMR measured in low fat consumers are in themselves risk factors for weight gain (Bouchard, 1996; Ravussin \& Gautier, 1999). In a study using Pima Indians $24 \mathrm{~h}$ RQ was correlated with subsequent changes in body weight and fat mass: subjects with a higher $24 \mathrm{~h}$ RQ (90th percentile) were 2.5 times more likely to gain $>5 \mathrm{~kg}$ than those with a lower (10th percentile) $24 \mathrm{~h}$ RQ in a follow-up period (Zurlo et al. 1990). Therefore the high RQ observed in the present studies may be a result of genetic factors or the habitual consumption of a high-carbohydrate diet; indeed there is no evidence to suggest that the high RQ observed among low fat consumers is not an inherited trait. This can be tested in a study in which low fat consumers are fed a high-fat diet for a period of time (i.e. $>7 \mathrm{~d}$ ) with subsequent measurement of RQ to determine if they, like high fat consumers, are equally able to match fat oxidation and intake; such a response should be expected as the study by Schrauwen et al. (1997) found that a group of twelve young, lean subjects were capable of adjusting fat oxidation to fat intake within $7 \mathrm{~d}$ when dietary fat content is increased, and it should be noted that the habitual fat intake of these subjects before dietary intervention was $29 \pm 1 \%$ energy indicating that this group were low consumers of fat.

Another finding highlighted in the present study was the differing metabolic response to carbohydrate and fat. Across both groups carbohydrate consumption raised metabolic rate (i.e. more DIT), $\mathrm{O}_{2}$ consumption and heart rate significantly more than an equi-energetic load of fat; this effect has been established previously (Stubbs, 1995). A recent study has coupled higher DIT following a carbohydrate load with greater satiety (Westerterp-Plantenga et al. 1999). Therefore the consumption of a high-carbohydrate diet would lead to greater satiety and improved appetite control via increased DIT. Interestingly, in a separate study low fat consumers have been found to show a better control of appetite than high fat consumers (Cooling \& Blundell, 1998a). Such a mechanism of increased satiety and increased DIT, when added to other properties of carbohydrate (low energy density, limited storage capacity and preferential oxidation) reveals that the consumption of a diet high in carbohydrate is unlikely to lead to a state of positive energy balance. However, the low fat consumer, because of their inability to match fat oxidation to fat intake in the short term, must be disciplined in order to avoid periodic high-fat eating episodes that would lead to acute positive energy balance.

\section{References}

Astrup A, Buemann B, Toubro S \& Raben A (1996) Defects in substrate oxidation involved in the predisposition to obesity. Proceedings of the Nutrition Society 55, 817-828.

Auwerx J \& Staels B (1998) Leptin. Lancet 351, 737-742.

Blundell JE \& Cooling J (2000) Routes to obesity: phenotypes, food choices and activity. British Journal of Nutrition 83, Suppl. 1, S33-S38.

Blundell JE \& Macdiarmid JI (1997) Fat as a risk factor for overconsumption: Satiation, satiety, and patterns of eating. Journal of the American Dietetic Association 97, Suppl., S63-S69.

Bouchard C (1996) Can obesity be prevented? Nutrition Reviews 54, S125-S130.

Calles-Escandon J \& Driscoll P (1995) Diet and body composition as determinants of basal lipolysis in humans. American Journal of Clinical Nutrition 61, 543-548.

Chang S, Graham B, Yakubu F, Lin D, Peters JC \& Hill JO (1990) Metabolic differences between obesity-prone and obesity-resistant rats. American Journal of Physiology 259, R1103-R1110.

Clapham JC, Arch JR, Chapman H, Haynes A, Lister C, Moore GB, Piercy V, Carter SA, Lehner I, Smith SA, Beeley LJ, Godden RJ, Herrity N, Skehel M, Changani KK, Hockings PD, Reid DG, Squires SM, Hatcher J, Trail B, Latcham J, Rastan S, Harper AJ, Cadenas S, Buckingham JA \& Brand MD (2000) Mice overexpressing human uncoupling protein-3 in skeletal muscle are hyperphagic and lean. Nature 406, 415-418.

Cooling J, Barth J \& Blundell JE (1998) The high-fat phenotype: Is leptin involved in the adaptive response to a high fat (high energy) diet? International Journal of Obesity 22, 1132-1135.

Cooling J \& Blundell JE (1998a) Are high-fat and low-fat consumers distinct phenotypes? Differences in the subjective and behavioural response to energy and nutrient challenges. European Journal of Clinical Nutrition 52, 193-201.

Cooling J \& Blundell JE (1998b) Differences in energy expenditure and substrate oxidation between habitual high fat and low fat consumers (phenotypes). International Journal of Obesity 22, 612-618.

Cooling J \& Blundell JE (2000) Lean male high- and low-fat phenotypes - different routes for achieving energy balance. International Journal of Obesity 24, 1561-1566. 
D’Alessio DA, Kavle EL \& Mozzoli MA (1988) Thermic effect of food in lean and obese men. Journal of Clinical Investigation 81, $1781-1789$.

Golay A \& Bobbioni E (1997) The role of dietary fat in obesity. International Journal of Obesity 21, Suppl. 3, S2-S11.

Macdiarmid JI, Cade JE \& Blundell JE (1996) High and low fat consumers, their macronutrient intake and body mass index: further analysis of the national diet and nutrition survey of British adults. European Journal of Clinical Nutrition 50, 505-512.

Macdiarmid JI, Hamilton KV \& Blundell JE (1995) Leeds High Fat Study: comparison of food choice and dietary patterns in High and Low Fat Consumers. Appetite 24, 293.

Macdiarmid JI, Hamilton V, Cade JE \& Blundell JE (1997) Are periodic high fat eating episodes a risk factor for weight gain? International Journal of Obesity 21, Suppl. 2, S116.

Margetts BM, Cade JE \& Osmond C (1989) Comparison of a food frequency questionnaire with a diet record. International Journal of Epidemiology 18, 868-873.

Mayes PA \& Felts JM (1967) Comparison of oxidative metabolism in starved, fat-fed and carbohydrate-fed rats. Biochemical Journal 103, 400-406.

Melanson KJ, Saltzman E, Russell RR \& Roberts SB (1997) Fat oxidation in response to four graded energy challenges in younger and older women. American Journal of Clinical Nutrition 66, 860-866.

Ravussin E \& Bogardus C (1989) Relationship of genetics, age, and physical fitness to daily energy expenditure and fuel utilization. American Journal of Clinical Nutrition 49, Suppl. 5, 968-975.

Ravussin E \& Gautier JF (1999) Metabolic predictors of weight gain. International Journal of Obesity 23, Suppl. 1, 37-41.

Ravussin E \& Tataranni PA (1997) Dietary fat and human obesity. Journal of the American Dietetic Association 97, Suppl. 7, S42-S46.

Reed DR, Tordoff MG \& Friedman MI (1991) Enhanced acceptance and metabolism of fats by rats fed a high-fat diet. American Journal of Physiology 261, R1084-R1088.

Saris WHM (1996) Physical inactivity and metabolic factors as predictors of weight gain. Nutrition Reviews 54, Suppl., S110-S115.

Schrauwen P, Hoppeler H, Billeter R, Bakker AHF \& Prendergast DR (2001) Fibre type dependent upregulation of human skeletal muscle UCP2 mRNA expression by high fat diet. International Journal of Obesity 25, 449-456.
Schrauwen P, van Marken Lichtenbelt WD, Saris WHM \& Westerterp KR (1997) Changes in fat oxidation in response to a high-fat diet. American Journal of Clinical Nutrition 66, 276-282.

Smith SR, de Jonge L, Zachwieja JJ, Roy H, Nguyen T, Rood J, Windhauser M, Volaufova J \& Bray GA (2000) Concurrent physical activity increases fat oxidation during the shift to a high-fat diet. American Journal of Clinical Nutrition $\mathbf{7 2}$, $131-138$.

Stubbs RJ (1995) Macronutrient effects on appetite. International Journal of Obesity 19, S11-S19.

Thomas CD, Peters JC, Reed GW, Abumrad NW, Sun M \& Hill JO (1992) Nutrient balance and energy expenditure during adlibitum feeding of high-fat and high-carbohydrate diet in humans. American Journal of Clinical Nutrition 55, 934-942.

Verboeket-van de Venne WPHG, Westerterp KR \& ten Hoor F (1994) Substrate utilisation in man: Effects of dietary fat and carbohydrate. Metabolism 43, 152-156.

Visser M, Deurenberg P, Staveren WA \& Hautvast JGAJ (1995) Resting metabolic rate and diet-induced thermogenesis in young and elderly subjects: relationship with body composition, fat distribution, and physical activity level. American Journal of Clinical Nutrition 61, 772-778.

Weir JB (1949) New method for calculating metabolic rate with special reference to protein metabolism. Journal of Physiology 109, 1-9.

Westerterp KR (1993) Food quotient, respiratory quotient and energy balance. American Journal of Clinical Nutrition 57, Suppl., 759S-765S.

Westerterp-Plantenga MS, Rolland V, Wilson SA \& Westerterp KR (1999) Satiety related to $24 \mathrm{~h}$ diet-induced thermogenesis during high protein/carbohydrate Vs high fat diets measured in a respiration chamber. European Journal of Clinical Nutrition 53, 495-502.

Weststrate JA (1993) Resting metabolic rate and diet-induced thermogenesis: a methodological reappraisal. American Journal of Clinical Nutrition 58, 592-601.

Young JC (1995) Meal size and frequency: effect on potentiation of the thermal effect of food by prior exercise. European Journal of Applied Physiology 70, 437-441.

Zurlo F, Lillioja S, Esposito-Del Puente A, Nyomba BL, Raz I, Saad MF, Swinburn BA, Knowler WC, Bogardus C \& Ravussin E (1990) Low ratio of fat to carbohydrate oxidation as predictor of weight gain: study of 24-h RQ. American Journal of Physiology 259, E650-E657. 